\title{
Role of Ultrasonoraphy in Gall bladder Dyskinsia as a cause of Functional Dyspepsia Symptoms
}

\author{
Ayman M. Abdelmofeed ${ }^{\mathrm{a}}$, Mohamed T. Awaad ${ }^{\mathrm{b}}$, Fatma A. Mohamed ${ }^{\mathrm{b}}$
}

${ }^{\mathrm{a}}$ Department of surgery, Benha faculty of medicine, Banha University, Egypt.

Department of diagnostic and interventional radiology, Benha faculty of medicine, Banha University, Egypt.

Correspondence to: Fatma A. Mohamed, Department of diagnostic and interventional radiology, Benha faculty of medicine, Banha University, Egypt.

Email:

fatmaatefbenha@gmail.com

Received: 9 August 2021

Accepted: 11 December 2021 examine most abdominal organs and often detect lesions that are not demonstrated by radiography.

\begin{abstract}
:
Background: Biliary dyskinesia (BD) is characterized by symptoms of biliary disease, no evidence of gallstones on ultrasonography (USG), and diminished gallbladder ejection fraction. Aim of the work: The aim of the current study is to evaluate the role of ultrasound in gall bladder dyskinesia. Patient and methods: 30 cases were referred from Tropical Medicine, All of these cases were complaining of generalized abdominal pain, heart burn, brubing and epigastric pain, Patients were asked about a history of endoscopic examination or any lab tests. Transabdominal ultrasound examination was carried out with the Patient lying flat using 3.5-5 Mhz convex probe. Results: the US mean volume premeal of the studied cases was 18.27 ( $\pm 2.16 \mathrm{SD})$ with range (14-21) $\mathrm{ml}$, the mean volume post-meal of the studied cases was 9.53 $( \pm 4.38 \mathrm{SD})$ with range $(3-17) \mathrm{ml}$ and the mean ejection fraction was $47.19( \pm 24.21$ SD) with range (15-85.7). Conclusion: ultrasound is valuable non-invasive tool in diagnosis of patients with dyskinesia symptoms. A skilled ultrasonographer can
\end{abstract} radiography.

Keywords: biliary dyskinesia; fatty meal; ultrasonography; functional dyspepsia 


\section{Introduction:}

"Dyspepsia" is the medical term for difficult digestion. Various symptoms in the upper abdomen, such as fullness,

discomfort, early satiation, bloating, heartburn, nausea, vomiting or epigastric pain and also lack of appetite is presented as dyspepsia. The potential causes of dyspepsia are known to include peptic ulcer disease, gastro-esophageal reflux, hiatus hernia, gallstones (GS) and functional dyspepsia (FD) (1).

FD is defined as the presence of chronic or recurrent pain or discomfort thought to relate the gastroduodenal region, in the absence of any organic, systemic, or metabolic disease that is likely to explain the symptoms (2).

Hence, correct differentiation between FD and other disease like peptic ulcer and gallstone related symptom are required. Several interventions have been performed for diagnosis of functional dyspepsia, including upper gastro-intestinal endoscopy, upper abdominal ultra sonography, and routine hematology and biochemistry screening blood tests (3).
Although, functional dyspepsia is not a lifethreatening disease, because of the high costs of diagnostic and treatment intervention (4).

It is required to select a cost effective management. Approximately $10 \%$ and $20 \%$ of asymptomatic patients became symptomatic within 5 and 20 years of diagnosis, respectively GS associated symptoms may be non-specific; it could be difficult to distinguish between symptomatic disease and FD. On the other hands, most GS is incidentally found during clinical evaluation of dyspepsia or routine ultrasonography (5).

Biliary dyskinesia (BD) is a controversial group of functional disorders of the biliary system which, according to the Rome III is comprised of two disorders, gallbladder dysfunction and sphincter of Oddi dysfunction (SOD). The etiology and pathogenesis of these disorders are poorly understood, (6).

Biliary dyskinesia (BD) is characterized by symptoms of biliary disease, no evidence of gallstones on ultrasonography (USG), and diminished gallbladder ejection fraction. The diagnosis is based on findings of abnormal gallbladder ejection fraction 
diagnosed by hepatobiliary scintigraphy before and after stimulation of gallbladder contraction with cholecystokinin (CCK). We used an easier diagnostic technique defined as ultrasonographic evaluation of fatty meal stimulated gallbladder contraction, employing USG with the diagnosis of biliary dyskinesia. (7). The study was conducted by USG to investigate the volume and contractility of the gallbladder (GB) in fasting conditions and $30 \mathrm{~min}$ after a standardized fatty meal (SFM) in patient complaining of functional dyspepsia, to evaluate its use as a new method in the diagnostic algorithm of BD.

\section{Patients and methods}

This prospective study was conducted between 12 December 2020 to February 2021 , on 30 patients with functional dyspepsia symptoms and US that performed for assessment the cause of dyspepsia referred from outpatient clinics to the radiology department of Tropical Hospital and gave their informed consent and approval of committees

The study was approved by the ethical committee of Benha faculty of medicine. An informed written consent in Arabic language will obtained from all participants. It includes all details about the study (tittle, objectives, methods, expected benefits and confidentiality data).

\section{Inclusion criteria:}

- Both sexes included

- Age> 18 years

\section{Exclusion criteria:}

- Refused to be included

- Traumatic patients

- Pregnancy.

\section{Patient preparation:}

All Patients were subjected to the following:-

- Proper clinical evaluation

- Full history taking:

- Full clinical examination.

- Patient preparation:

- All Patients will be fasting for 6-8 hours at least before examination.

- Transabdominal ultrasound examination was carried out with the Patient lying flat using 3.5-5 Mhz convex probe. fasting and after having a fatty meal by $30 \mathrm{~min}$

- Dis infected gel solution was used as acoustic medium.

- Different positions were used as supine and lateral oblique and decubitus position to visualize Different abdominal organs.

- Images were recorded in soft ( \pm hard) copy images measuring the volume of 
gall bladder and common bile duct fasting and after taking a fatty meal.

- Full abdominal and pelvic examination was carried out including the digestive system, solid organs as well as any additional.

- Any positive finding was documented.

\section{Statistical Analysis:-}

The statistical analysis was performed using Excel program (2010)of windows(10). Statistical analysis was performed using MedCalc-version 17.9.7(MedCalc Software bib, Ostend, Belgium).Normally distributed numerical variables were presented as mean \pm SD.Categorical variables were presented as number $(\%)$. The level of significance was calculated as:

$\mathrm{p}>0.05$ nonsignificant, $\mathrm{p}<0.05$ significant, $\mathrm{p}<0.01$ highly significant

\section{Results:}

Among the studied cases there were 17 $(53.3 \%)$ males and $13(43.3 \%)$ females with mean age of $39.2( \pm 10.53 \mathrm{SD})$ and range (24-59) years (table 1)

There were $22(73.3 \%)$ with burning stomach pain, 16 (53.3) with bloating, 19 (63.3\%) with burping, 11 (36.7\%) with nausea, $14(46.7 \%)$ with heartburn and 22 $(73.3 \%)$ with vomiting (figure 1$)$.
The mean volume pre-meal of the studied cases was $18.27( \pm 2.16 \mathrm{SD})$ with range (1421) $\mathrm{ml}$, the mean volume post-meal of the studied cases was $9.53( \pm 4.38$ SD $)$ with range (3-17) $\mathrm{ml}$ and the mean ejection fraction was $47.19( \pm 24.21 \mathrm{SD})$ with range (15-85.7) (table 2).

Among the studied cases there were 13 (43.3\%) with dyskinesia (figure 2)

There was no statistical significant relation between dyskinesia and symptoms of dyspepsia (table 3).

There was high statistical significant relation between dyskinesia and volume post-meal and ejection fraction (table 4).

Case (1); Clinical data: Female patient 59 years old presented with nausea and vomiting. US findings: Gall bladder ejection fraction $=33 \%$. Diagnosis: Gall bladder dyskinesia (figure 3 A \& B).

Case (2); Clinical data: Female patient 41 years old presented with burning stomach pain. US findings: Gall bladder ejection fraction $=30.08 \%$. Diagnosis; Gall bladder dyskinesia (figure 4 A \& B)

Case (3); Clinical data: Male patient 55 years old presented with burping and abdominal bloating. US findings: Gall 
bladder ejection fraction $=80 \%$. Diagnosis; $\quad$ Normal gall bladder function (figure 5 A \& B)

Table 1: Distribution of studied cases as regard demographic data

\begin{tabular}{ccc}
\hline & \multicolumn{2}{c}{ Cases } \\
$(\mathbf{n}=\mathbf{3 0})$
\end{tabular}

Table 2: Distribution of studied cases as regard Ultrasound outcome

\begin{tabular}{lc}
\hline & $\begin{array}{c}\text { Cases } \\
(\mathbf{n}=\mathbf{3 0})\end{array}$ \\
\hline Volume pre-meal (mL) & \\
Min. - Max. & $14-21$ \\
Mean \pm SD. & $18.27 \pm 2.16$ \\
Volume post-meal (mL) & \\
Min. - Max. & $3-17$ \\
Mean \pm SD. & $9.53 \pm 4.38$ \\
Ejection fraction (\%) & \\
Min. - Max. & $15-85.7$ \\
Mean \pm SD. & $47.19 \pm 24.21$ \\
\hline
\end{tabular}

Table 3: Relation between dyskinesia and symptoms of dyspepsia

\begin{tabular}{lcccccc}
\hline & \multicolumn{2}{c}{$\begin{array}{c}\text { Dyskinesia } \\
(\mathbf{n}=\mathbf{1 3})\end{array}$} & \multicolumn{2}{c}{$\begin{array}{c}\text { Non-dyskinesia } \\
(\mathbf{n = 1 7})\end{array}$} & Test & p \\
Symptoms of dyspepsia & No. & $\%$ & No. & $\%$ & & \\
\hline Burning stomach pain & 8 & 61.5 & 14 & 82.4 & $\chi^{2}=1.632$ & 0.201 \\
Bloating & 6 & 46.2 & 10 & 58.8 & $\chi^{2}=0.475$ & 0.491 \\
Burping & 6 & 46.2 & 13 & 76.5 & $\chi^{2}=2.916$ & 0.088 \\
Nausea & 5 & 38.5 & 6 & 35.3 & $\chi^{2}=0.032$ & 0.858 \\
Heartburn & 6 & 46.2 & 8 & 47.1 & $\chi^{2}=0.002$ & 0.961 \\
Vomiting & 10 & 76.9 & 12 & 70.6 & $\chi^{2}=0.151$ & 0.697 \\
\hline
\end{tabular}

$\chi^{2}$ : Chi square test

$\mathrm{p}$ : $\mathrm{p}$ value for comparing between the studied groups 
Table 4: Relation between dyskinesia and Ultrasound outcome

\begin{tabular}{|c|c|c|c|c|}
\hline & $\begin{array}{c}\text { Dyskinesia } \\
(\mathrm{n}=13)\end{array}$ & $\begin{array}{c}\text { Non-dyskinesia } \\
\quad(\mathbf{n}=17)\end{array}$ & $\mathbf{t}$ & $\mathbf{p}$ \\
\hline \multicolumn{5}{|c|}{ Volume pre-meal (mL) } \\
\hline Min. - Max. & $14-21$ & $15-21$ & 0.755 & 0.457 \\
\hline Mean \pm SD. & $17.92 \pm 2.43$ & $18.53 \pm 1.97$ & & \\
\hline \multicolumn{5}{|c|}{ Volume post-meal (mL) } \\
\hline Min. - Max. & $11-17$ & $3-12$ & 6.299 & $<0.001^{*}$ \\
\hline Mean \pm SD. & $13.31 \pm 1.75$ & $6.65 \pm 3.48$ & & \\
\hline \multicolumn{5}{|c|}{ Ejection fraction $(\%)$} \\
\hline Min. - Max. & $15-33.3$ & $35.3-85.7$ & 7.011 & $<0.001^{*}$ \\
\hline Mean \pm SD & $25.47 \pm 5.66$ & $63.81 \pm 19.01$ & & \\
\hline
\end{tabular}

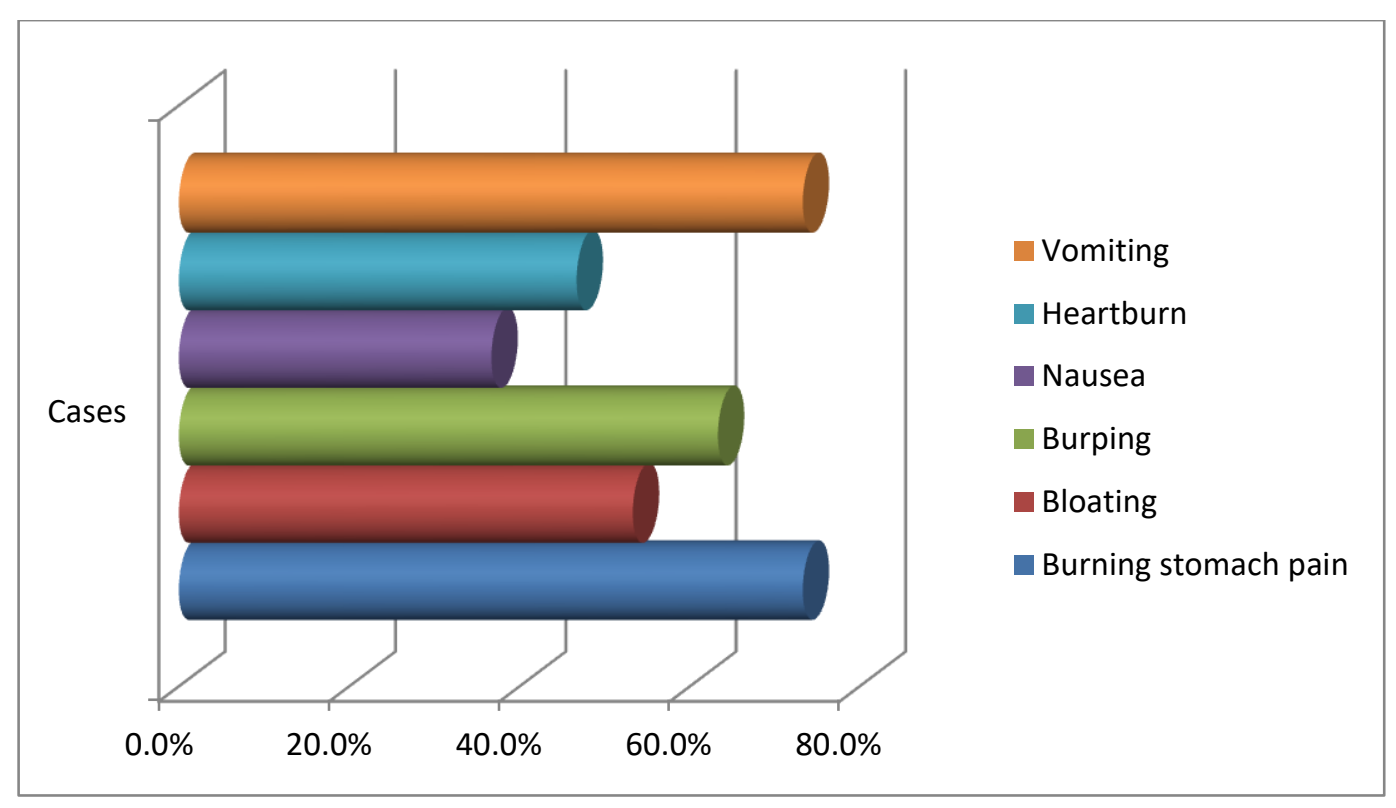

Fig (1): Distribution of studied cases as regard Symptoms of dyspepsia 
Benha medical journal, vol. 39, special issue (radiology), 2022

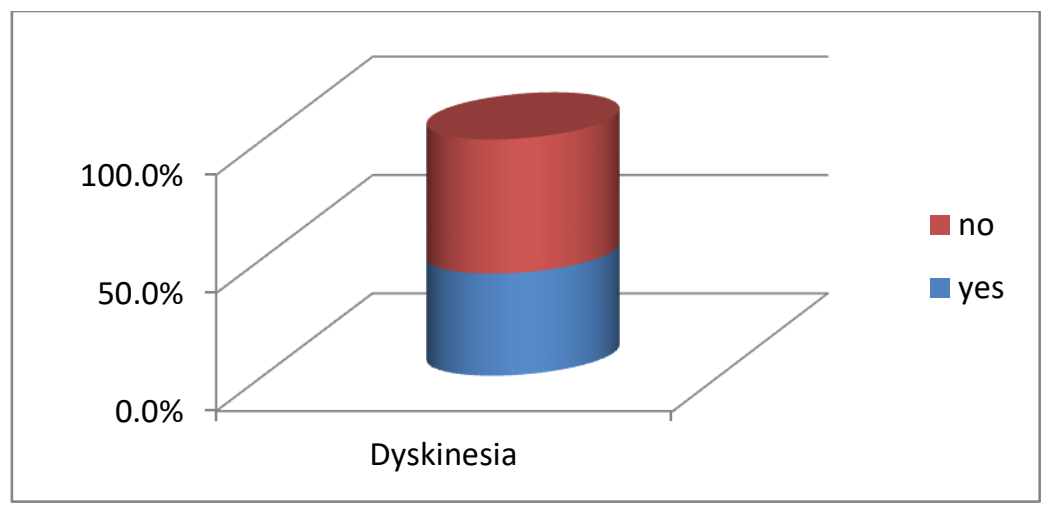

Fig (2): Prevalence of dyskinesia among dyspepsia patients



Fig( 3 )A: ultra sound image showing the volume of gall bladder fasting 6 hours.

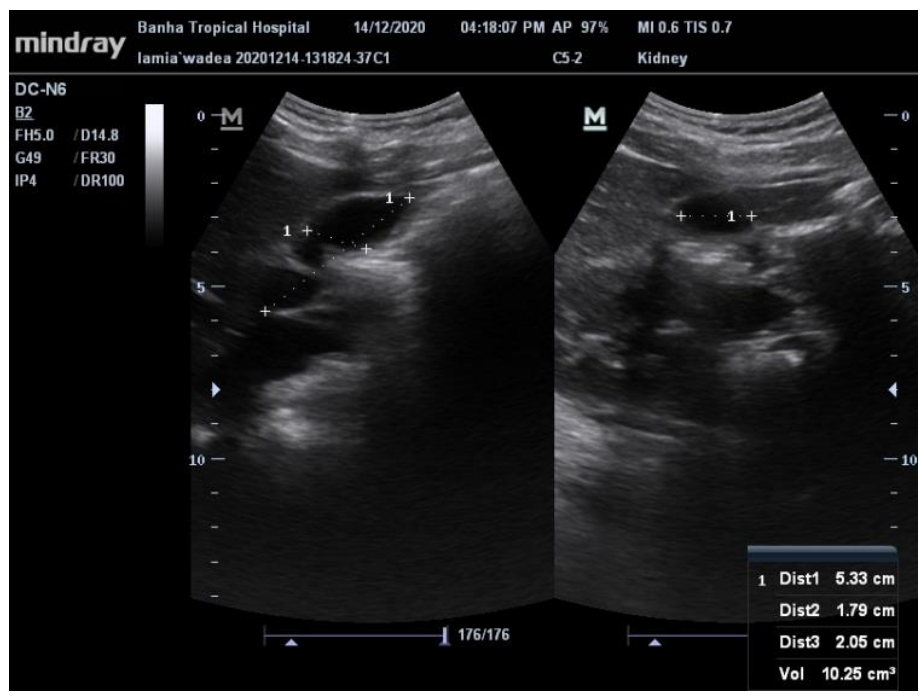

Fig( 3) B: ultra sound image showing the volume of gall bladder after taking a fatty meal by $30 \mathrm{~min}$.

\section{E.F $=$ pre meal volume - post mal volume / pre meal volume $\times 100$}

so E.F 15-10/10 x 100= 33\% 




Fig(4) A: ultra sound image showing the volume of gall bladder fasting 6 hours.

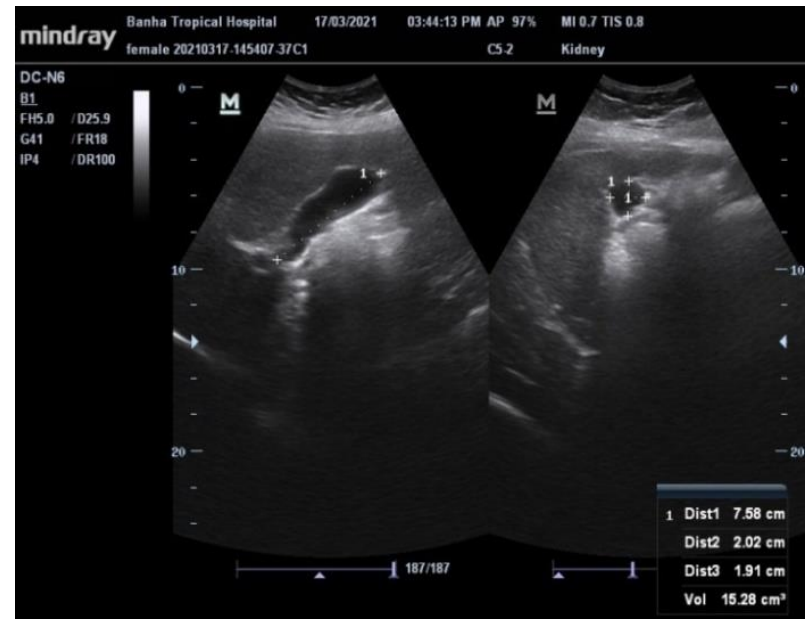

Fig (4) B: ultra sound image showing the volume of gall bladder fasting 6 hours meal by $30 \mathrm{~min}$.

$$
\begin{gathered}
\text { E.F }=\text { pre meal volume }- \text { post mal volume } / \text { pre meal volume } \times 100 \\
\text { So E.F } 19.89-15.29 / 15.29 \times 100=30.08 \%
\end{gathered}
$$

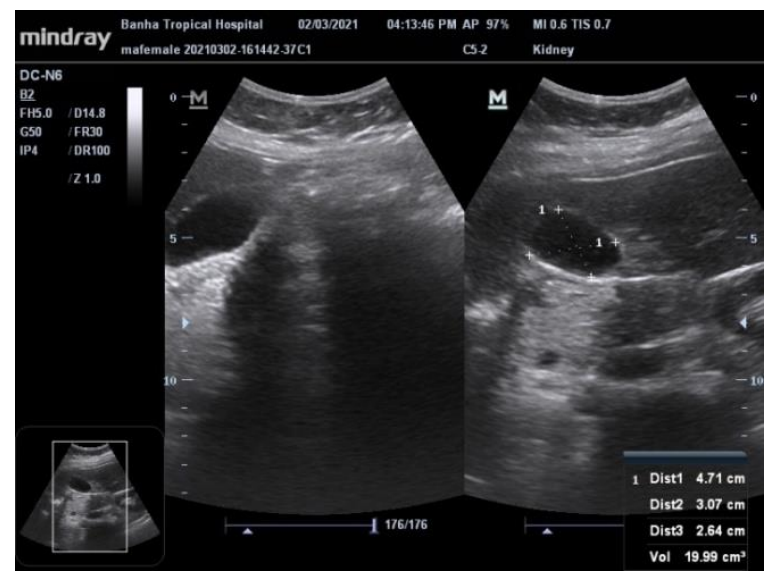

Fig (5)A: ultra sound image showing the volume of gall bladder fasting 6 hours. 


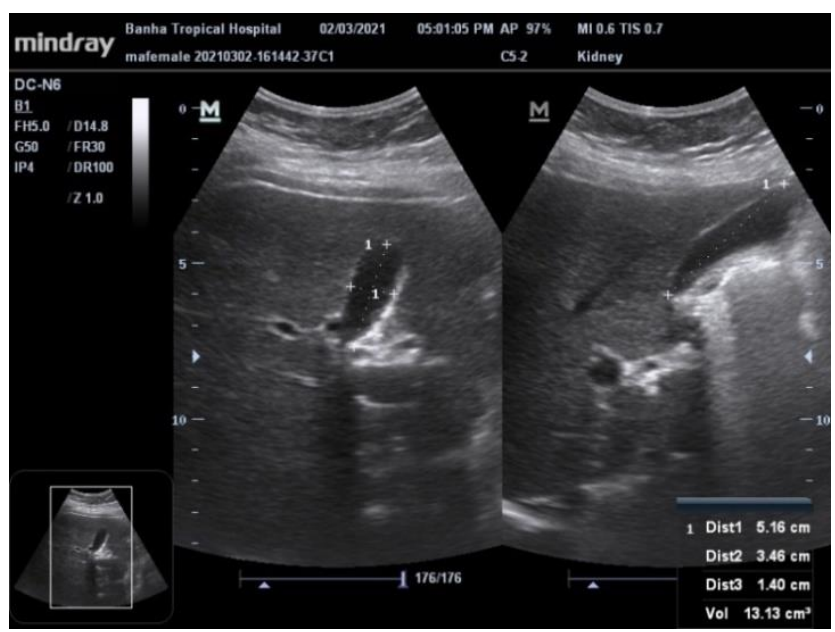

Fig(5) B: ultra sound image showing the volume of gall bladder after taking a fatty meal by $30 \mathrm{~min}$.

\section{E.F $=$ pre meal volume - post mal volume $/$ pre meal volume $\times 100$}

So E.F 19.99-13.13/13.13 x 100= 80\%

\section{Discussion:}

Thirty patients with functional dyspepsia symptoms were included in our study. The number of female patients was 13the number of male patients was 17 and the patients' mean age was 30 years. The median age was 39 years, ranging from 24to 59 years, These results near the results of a previous study (8) study in which functional dyspepsia symptoms in 40 patients was investigated. The mean age of the 40 patients was $43.2 \pm 2.3$ years ((SEM) range, 20-72 years), and five of the subjects $(12.5 \%)$ were men.

In this study the main symptoms were shows that among the studied cases there were 22 (73.3\%) with burning stomach pain, 16
(53.3) with bloating, 19 (63.3\%) with burping, $11(36.7 \%)$ with nausea, 14 (46.7\%) with heartburn and 22 (73.3\%) with vomiting. this was matched with previous study, (9).

In this study ultrasound (US) finding, that the mean volume pre-meal of the studied cases was 18.27 ( $\pm 2.16 \mathrm{SD})$ with range (1421) $\mathrm{ml}$, the mean volume post-meal of the studied cases was $9.53( \pm 4.38$ SD) with range (3-17) $\mathrm{ml}$ and the mean ejection fraction was $47.19( \pm 24.21 \mathrm{SD})$ with range (15-85.7).

Among the studied cases there were 13 (43.3\%) with dyskinesia. there was high 
statistical significant relation between dyskinesia and volume post-meal and ejection fraction there was no statistical significant relation between dyskinesia and symptoms of dyspepsia. From this study, it became clear that abdominal ultrasound is a valuable tool for evaluating patients with gall bladder dyskinesia.

The use of ultrasound must be further explored because of its higher accuracy in volume calculation. of gall bladder and in diagnosis of gall bladder dyskinesia.

\section{Conclusion:}

Ultrasonographic evaluation of fatty meal stimulated gallbladder contraction provides relatively reliable and reproducible results. Thus it can be used for scanning in patients with biliary symptoms as a prior modality to CCK-HBS since it is a relatively easier, safer and available method with which to make a definitive diagnosis of BD. The patients with symptoms of biliary disease and no evidence of gallstones on USG should be evaluated by the method proposed in this study before the routine laboratory and radiologic tests.

\section{References:}

1. Brun R, Kuo B. Functional dyspepsia. Therap Adv Gastroenterol. 2010;3(3):145-64.

2. Agana M, Frueh J, Kamboj M, Patel DR, Kanungo S. Common metabolic disorder (inborn errors of metabolism) concerns in primary care practice. Ann Transl Med. 2018;6(24).

3. Jones RH. Approaches to uninvestigated dyspepsia. Gut. 2002;50(suppl 4):iv42-6.

4. Moayyedi P, Mason J. Clinical and economic consequences of dyspepsia in the community. Gut. 2002;50(suppl 4):iv10-2.

5. Froutan Y, Alizadeh A, Mansour-Ghanaei F, Joukar F, Froutan H, Bagheri FB, et al. Gallstone disease founded by ultrasonography in functional dyspepsia: prevalence and associated factors. Int $\mathrm{J}$ Clin Exp Med. 2015;8(7):11283.

6. Goussous N, Kowdley GC, Sardana N, Spiegler E, Cunningham SC. Gallbladder dysfunction: how much longer will it be controversial? Digestion. 2014;90(3):147-54.

7. Çay A, İmamoğlu M, Sarihan H, Ahmetoğlu A. Ultrasonographic evaluation of fatty meal stimulated gallbladder contraction in the diagnosis of biliary dyskinesia in children. Acta Pædiatrica. 2006;95(7):838-42.

8. Akhondi-Meybodi M, Aghaei MA, Hashemian $Z$. The role of diet in the management of nonulcer dyspepsia. Middle East J Dig Dis. 2015;7(1):19.

9. Sun X, Ke M, Wang Z. Clinical features and pathophysiology of belching disorders. Int $\mathbf{J}$ Clin Exp Med. 2015;8(11):21906.

To cite this article: Ayman M. Abdelmofeed, Mohamed T. Awaad, Fatma A. Mohamed. Role of Ultrasonoraphy in Gall bladder Dyskinsia as a cause of Functional Dyspepsia Symptoms. BMFJ 2022; 39 (Radiology): 234-243. DOI: 10.21608/bmfj.2021.89386.1454 